\title{
Convergence of Energy Intensity in OECD Countries
}

\author{
Cem Canel${ }^{1}$, Selahattin Guris², Burak Guris², Begüm Öktem³ ${ }^{2}$ Recep 0ktem³ \\ ${ }^{1}$ Department of Analytics, Information Systems and Supply Chain, University of North Carolina Wilmington, Wilmington, USA \\ ${ }^{2}$ Department of Econometrics, Faculty of Economics, Marmara University, Istanbul, Turkey \\ ${ }^{3}$ Department of Accounting and Tax Implications, Marmara University, Istanbul, Turkey \\ Email: canelc@uncw.edu
}

How to cite this paper: Canel, C., Guris, S., Guris, B., Öktem, B. and Oktem, R. (2017) Convergence of Energy Intensity in OECD Countries. Modern Economy, 8, 946-958.

https://doi.org/10.4236/me.2017.87066

Received: June 17, 2017

Accepted: July 23, 2017

Published: July 26, 2017

Copyright (c) 2017 by authors and Scientific Research Publishing Inc. This work is licensed under the Creative Commons Attribution International License (CC BY 4.0).

http://creativecommons.org/licenses/by/4.0/

\section{c) (†) Open Access}

\begin{abstract}
This paper investigates whether there is energy intensity convergence in the Organization for Economic Cooperation and Development (OECD) countries or not by using annual data from the 1980-2011 period. OECD countries are Australia, Austria, Belgium, Canada, Chile, Denmark, Finland, France, Germany, Greece, Ireland, Italy, Japan, North Korea, South Korea, Luxembourg, Mexico, Netherlands, New Zealand, Norway, Portugal, Spain, Sweden, Switzerland, Turkey, UK, and USA. Energy intensity is measured by the ratio of total energy consumption to total output. Energy intensity measures the energy consumption of an economy and its overall energy efficiency. We used linear and nonlinear unit root tests from the recent literature to accomplish this goal. An analysis of the test results shows that there is no convergence in Chile, Finland, Greece, Ireland, South Korea, Luxembourg, Mexico, Netherlands, New Zealand, Portugal, Spain, Sweden, Switzerland, and the UK. These countries should start implementing changes to their energy policies to achieve effective energy use.
\end{abstract}

\section{Keywords}

Energy Intensity, Nonlinear Unit Root Tests

\section{Introduction}

Energy intensity is measured by the ratio of total energy consumption to total output, measured as Gross Domestic Product (GDP). It measures the energy consumption of an economy and its overall energy efficiency. High energy intensities indicate a high price or cost of converting energy into GDP. Low energy intensity indicates a lower price or cost of converting energy into GDP. This ratio is a measurement used in the comparison of the countries in this 
study. The oil crises experienced in the 1970's have revealed the effects of energy on the economies of countries in different parts of the world. Several studies in this area focused on the correlation between energy consumption and growth [1] [2] [3] [4]. However, there are relatively limited studies on energy effects and energy intensity.

Nilsson [5] investigated energy intensities for thirty-one countries which are evaluated from 1950 to 1988, using a purchasing power parity-based GDP measure and United Nations energy statistics. The energy intensities of low-income countries are similar to those of high-income countries when comparisons include noncommercial energy. Energy intensities have decreased for fifteen out of the thirty-one countries studied. The analysis indicates that there is a level of energy intensity, between 0.25 and 0.5 per 1000 (1980) dollars, to which many countries are converging.

Pen and Sevi [6] evaluated the convergence of energy intensities for a group of ninety-seven countries from 1971 to 2003. Convergence is tested using new methods. Applications of several unit-root tests, as well as a stationary test, uniformly reject the global convergence hypothesis. Non-convergence is less strongly rejected for Middle East, OECD and Europe sub-groups. The introduction of possible structural breaks in the analysis marginally provides more support to the convergence hypothesis. Liddle [7] investigated convergence in energy intensity using two new large data sets: A one hundred eleven-country sample spanning from 1971 to 2006, and a one hundred thirty-four-country sample spanning from 1990 to 2006. Both data sets confirm continued convergence. However, the larger data set, which adds the former Soviet Union Republics and additional Balkan countries, indicates greater convergence over the more recent time-frame. Further investigation of geographical differences reveals that the OECD and Eurasian countries show considerable, continued convergence, while the Sub-Saharan African countries show convergence amongst themselves, but at a slower rate than the OECD and Eurasian countries. By contrast, Latin American and the Caribbean and the Middle East and North African countries exhibit no convergence to divergence in energy intensity.

Ezcurra [8] investigated the spatial distribution of energy intensities in ninetyeight countries between 1971 and 2001. The results reveal the presence of a convergence process in energy efficiency levels across the sample countries during the study period, as a consequence of the evolution experienced by those countries located at both ends of the distribution in 1971.

Since economic convergence can occur if poorer countries or regions grow more rapidly than the richer countries and regions, the notation of economic convergence deals with the important question of whether poorer countries grow at a faster rate than richer countries [9]. In general, the concept of convergence may be taken into account under three categories. The first one is $\beta$ type convergence. This convergence type is defined as follows in the study conducted by Barro and Sala-i-Martin [10]:

$$
\frac{1}{T} \log \left(\frac{y_{i, t}}{y_{i, t-T}}\right)=a-\left[\frac{1-\mathrm{e}^{-\beta T}}{T}\right] \cdot \log \left(y_{i, t-T}\right)+u_{i, t}
$$


Here, $y_{i, t-T}$ indicates the real income per capita in the starting year and $y_{i, t}$ indicates the income per capita in the year of $t . \quad \beta$ is the coefficient that indicates the convergence rate. This coefficient must be statistically significant. If the coefficient is positively marked, occurrence of convergence is mentioned and if it is negatively marked, the divergence is mentioned.

The second convergence type is $\sigma$ type convergence. In this convergence type, standard deviation value is used for measuring the expansion. The decrease of standard deviation in terms of time indicates occurrence of convergence. If the standard deviation increases in terms of the time, the divergence comes into question. Sigma stands for the standard deviation of log GDP per capita values. In case of convergence, sigma shows a negative trend in a time period. This also means that inequalities are diminishing. Sigma convergence refers to a reduction in the dispersion of income levels across economies.

The third convergence type is stochastic convergence. The stochastic convergence was introduced by Carlino and Mills [11] and Bernard and Darlauf [12]. In their studies, Bernard and Durlauf [12] define the convergence as follows:

$$
\lim _{k \rightarrow \infty} \mathrm{E}\left(y_{i, t+k}-y_{j, t+k} \mid I_{t}\right)=0
$$

where $y_{i}$ is the $\log$ real GDP per capita in country $i, I_{t}$ is the information set available at period $t$. In other words, it means convergence of $i$ and $j$ economies to each other that the logarithms of production level per capita in a specific $t$ time was equal for two countries. Stochastic convergence asks whether permanent movements in one country's per capita income are associated with permanent movements in other countries' income [12]. The method that is frequently used for empirically testing the stochastic convergence is the use of unit root tests.

In this study, we investigate the convergence of energy intensity among OECD countries (Australia, Austria, Belgium, Canada, Chile, Denmark, Finland, France, Germany, Greece, Ireland, Italy, Japan, North Korea, South Korea, Luxembourg, Mexico, Netherlands, New Zealand, Norway, Portugal, Spain, Sweden, Switzerland, Turkey, UK, USA) and use a nonlinearity test established by Harvey et al., [13]. The main advantage of this test is that results are not affected by the level of stationary. Concerning nonlinearity findings, the convergence of energy intensity among OECD countries is reviewed by using the nonlinear unit root tests of Kapetanios et al., [14] and tests of Kruse [15] and symmetric and unit root tests allowing for symmetric and asymmetric nonlinear adjustments which were developed by Sollis [16]. In this study, we considered the sensitivity of the relevant tests to lag length and selected appropriate lag length which was not used in various studies using these tests. For the series that was determined as linear, we used two structural breaks unit root test developed by Narayan and Popp [17] since it is considered to be better than other structural break tests.

The outline of this paper as follows. In section two, we explain the data and the empirical methodology, section three presents the empirical results, and the 
last section provides the conclusions.

\section{Data and Empirical Methodology}

\subsection{Data Description}

This paper investigates the convergence of energy intensity in OECD countries using annual data covering the 1980-2011 period (as Italy does not have data belonging to 1980, 1981-2011 data were used). The energy intensity is measured as Total Energy Consumption per Dollar of GDP (using purchasing power parity). All data are from the US Energy Information Administration. Stochastic convergence is introduced by Carlino and Mills [11] and Bernard and Darlauf [12]. According to Bernard and Darlauf [12], if the logarithm of the analyzed variable $y_{i j t}$, follows a stationary process, stochastic convergence occurs.

$$
y_{i j t}=\log Y_{i t}-\log Y_{j t}
$$

where $y_{i j t}$ is the analyzed variable, $Y_{i t}$ is the variable value for unit $i$ at time $t$ and $Y_{j t}$ is the variable value for unit $\mathrm{j}$ at time $t$.

Carlino and Mills [11] define deviation series as $D y_{j t}=\bar{y}_{t}-y_{j t}$ where $y_{j t}$ is the analyzed variable value for unit $j$ at time $t$ and $\bar{y}$ is the average value of all units at time $t$. Rejection of the unit root hypothesis gives evidence of stochastic convergence. We define $Y_{i t}$ as follows

$$
y_{i t}=\ln \left(\frac{x_{i t}}{\bar{x}_{t}}\right)
$$

where $x_{i t}$ is energy intensity of country $i, \bar{x}_{t}$ is the average energy intensity of OECD.

\subsection{Empirical Methodology}

The method frequently used for empirically testing the stochastic convergence is the use of unit root tests. If the series is stationary, a finding is obtained regarding that there is convergence, and if it is not stationary, a finding is achieved about that there is no convergence. The biggest problem in the studies that were carried out based on the unit root tests was the selection of the right test. Different tests selected yield different results and the findings obtained show differences. The standard tests for unit root and cointegration all have lower power in the presence of misspecified dynamics [18]. Perron [19] show that when existing structural break ignored the conventional unit root tests will be biased towards not rejecting a false null of a unit root. When researchers cannot determine a correct model specification and identify the number or form of breaks, there can be sharp decreases in test power [18]. A similar phenomenon occurs in nonlinear models. If there is nonlinearity in the data, linear unit root tests come across with power problem, and test results are biased to non-rejection of the null hypothesis [20].

A unit root test appropriate for the data structure is selected to prevent biased results. The series are tested using nonlinearity test developed by Harvey et al., 
[13]. We selected this test because it has the advantage of not being affected by stationary levels of the variables. We used nonlinear unit root tests developed by Kapetanios et al. [14], Kruse [15] and Sollis [16] for the series on which nonlinearity finding was obtained. The reason for selecting these tests was that they are based on winter regimes smooth transition model which is considered to be more appropriate for the economic structure and have a better power compared to previous tests. We used two structural break unit root test developed by Narayan and Popp [17] for the series of which linearity was determined. The main advantage of this test is that it allows for structural breaks within the scope of the null hypothesis. In their studies, Narayan and Popp [21]) compared performances of structural break unit root tests and demonstrated that Narayan and Popp [17] test has a better performance compared to other structural tests.

\subsubsection{Nonlinearity Test}

In this study, we used nonlinearity test developed by Harvey et al., (2008) for determination of nonlinearity properties of the series because it is not affected by stationary levels of the variables. The model to use under the assumption that time series is stationary $(I(0))$ for implementation of the test developed by Harvey et al., [13] is shown as follows:

$$
y_{t}=\beta_{0}+\beta_{1} y_{t-1}+\beta_{2} y_{t-2}^{2}+\beta_{3} y_{t-3}^{3}+\sum_{j=1}^{p} \beta_{4, j} \Delta y_{t-j}+\varepsilon_{t}
$$

where $\Delta$ is the first difference operator, $p$ is the number of lags. As suggested in the studies of Harvey et al., [13], maximum number of lags is calculated as (number of lags) $p_{\max }=\operatorname{int}\left(8\left(\frac{T}{100}\right)^{1 / 4}\right)$ and optimal number of lags can be determined by means of the sequential testing method using a $10 \%$ significance level. The null hypotheses to be used for the test are in the form of

$$
H_{0, I(0)}: \beta_{2}=\beta_{3}=0 \text { (linearity) }
$$

moreover, the alternative hypothesis

$$
H_{1, I(0)}: \beta_{2} \neq 0 \text { and/or } \beta_{3} \neq 0 \text { (nonlinearity). }
$$

The test statistic is calculated as follows:

$$
W_{0}=T\left(\frac{R S S_{0}^{r}}{R S S_{0}^{u}}-1\right)
$$

Here, $T$ is the number of observations, $R S S_{0}^{r}$ and $R S S_{0}^{u}$ are the residual sum of squares from the unrestricted and restricted form of the model 1 , respectively.

The model to use under the assumption of that time series is not stationary $(I(1))$ is shown as follows:

$$
\Delta y_{t}=\lambda_{1} \Delta y_{t-1}+\lambda_{2}\left(\Delta y_{t-1}\right)^{2}+\lambda_{3}\left(\Delta y_{t-1}\right)^{3}+\sum_{j=1}^{p} \lambda_{4, j} \Delta y_{t-j}+\varepsilon_{t}
$$


The null hypotheses to use for the test are in the form of $H_{0, I(1)}: \lambda_{2}=\lambda_{3}=0$ (linearity) and alternative hypothesis

$$
H_{1, I(1)}: \lambda_{2} \neq 0 \text { and/or } \lambda_{3} \neq 0 \text { (nonlinearity). }
$$

The test statistic is calculated as follows:

$$
W_{1}=T\left(\frac{R S S_{1}^{r}}{R S S_{1}^{u}}-1\right)
$$

where $R S S_{0}^{r}$ and $R S S_{0}^{u}$ are the residual sum of squares from the unrestiricted and restiricted form of the model 2 , respectively.

In their studies, Harvey et al., [13] suggested the below test statistic that is calculated through aforementioned two tests' statistics when stationary properties of the time series are not exactly known.

$$
W_{\lambda}=\{1-\lambda\} W_{0}+\lambda W_{1}
$$

where $\lambda$ is a function that convergences in probability to 0 if time series is $I(0)$ and to 1 if time series is $I(1) . W_{\lambda}$ is asymptotically distributed as $\chi_{2}^{2}$.

\subsubsection{Nonlinear Unit Root Test}

1) Kapetanios, Shin, Snell (2003) Unit Root Test

Kapetanios et al., [14] provide an alternative framework for a test of the null of a unit root process against an alternative of nonlinear exponential smooth transition autoregressive (ESTAR) process, which is globally stationary. Kapetanios et al., [14] proposed $y_{t}$ to be a mean zero stochastic process, a univariate smooth transition autoregressive of order 1, namely STAR(1) model as follows,

$$
y_{t}=\beta y_{t-1}+\gamma y_{t-1} \Theta\left(\theta ; y_{t-d}\right)+\varepsilon_{t}, \quad t=1, \cdots, T
$$

in which $\beta$ and $\gamma$ are unknown parameters and $\varepsilon_{t} \sim$ iid $\left(0, \sigma^{2}\right)$. The transition function adopted exponential form, $\Theta\left(\theta ; y_{t-d}\right)=1-\exp \left(-\theta y_{t-d}^{2}\right)$ where they assumed that $\theta \geq 0$, and $d \geq 1$ is the lag parameter. The exponential transition function is limited to be between zero and one. Using (10) and (11) obtained an ESTAR model, $y_{t}$ is shown as follows:

$$
y_{t}=\beta y_{t-1}+\gamma y_{t-1}\left[1-\exp \left(-\theta y_{t-d}^{2}\right)\right]+\varepsilon_{t}, \quad t=1, \cdots, T
$$

where using parameter conveniently, it is rewritten as,

$$
\Delta y_{t}=\phi y_{t-1}+\gamma y_{t-1}\left[1-\exp \left(-\theta y_{t-d}^{2}\right)\right]+\varepsilon_{t}, \quad t=1, \cdots, T
$$

In which $\phi=\beta-1$. If $\theta$ is positive, it effectively determines the speed of mean reversion. Kapetanios et al., [14] demonstrate in case of $\phi=0$ and $d=1$ specific ESTAR model as,

$$
\Delta y_{t}=\gamma y_{t-1}\left[1-\exp \left(-\theta y_{t-1}^{2}\right)\right]+\varepsilon_{t}
$$

In test procedures, specific parameter $\theta$, which is zero under the unit root null hypothesis and positive under the globally stationary ESTAR alternative hypothesis is $H_{0}: \theta=0, H_{1}: \theta>0$ Testing the null hypothesis directly is not feasible, $\gamma$ is not identified under the null. To overcome this problem, $t$-type 
test statistics are used. They demonstrate a first-order Taylor series approximation to the ESTAR model under the null, the auxiliary regression,

$$
\Delta y_{t}=\delta y_{t-1}^{3}+\text { error }
$$

They obtain the $t$-statistic for $\delta<0$ against $\delta<0$ as $t_{N L}=\hat{\delta} /$ s.e. $(\hat{\delta})$ where $\hat{\delta}$ is the OLS estimate of $\delta$ and s.e. $(\hat{\delta})$ is the standard error of $\hat{\delta}$. Kapetanios et al., [14] obtain the asymptotic critical value of $t_{N L}$ statistics for three cases in their study.

\section{2) Kruse (2011) Unit Root Test}

Kruse's [15] study shows that in real world examples, the possibility of non-zero location parameter $(c \neq 0)$ is imminent. For that reason, Kruse [15] extends the Kapetanios et al., [14] nonlinear unit root test to allow for a nonzero location parameter $(c \neq 0)$ [2]. Kruse [15] suggested estimation of belowmentioned model under the assumption of $c \neq 0$.

$$
\Delta y_{t}=\phi y_{t-1}\left(1-\exp \left\{-\gamma\left(y_{t-1}-c\right)^{2}\right\}\right)+\varepsilon_{t}
$$

This equation is transformed into the below form by using Taylor approximation as utilized in the study by Kapetanios et al., [14].

$$
\Delta y_{t}=\delta_{1} y_{t-1}^{3}+\delta_{2} y_{t-1}^{2}+\sum_{j=1}^{p} \varphi_{j} \Delta y_{t-j}+\varepsilon_{t}
$$

Concerning this, Kruse [15] proposes a $\tau$ test which is a version of the Abadir and Distaso [22] for testing the null hypothesis of unit root $\left(H_{0}: \delta_{1}=\delta_{2}=0\right)$ against Globally stationary ESTAR process $\left(H_{1}: \delta_{1}<0, \delta_{2} \neq 0\right)$. For this test statistic, the critical values are tabulated in the study by Kruse [15].

\section{3) Sollis (2009) Unit Root Test}

KKS test is based on the assumption of that mean reversion is symmetric at every point. This assumption means that negative and positive deviations have the same effect. Sollis [16] stretched this assumption and developed a new test procedure that allows for symmetric or asymmetric nonlinear adjustments. In this test, the speed of mean reversion is different depending on the sign of the shock, not only the size [23]. The model to use for the test based on the AESTAR model developed by Sollis [16] is as follows:

$$
\Delta y_{t}=G\left(\gamma_{1}, y_{t-1}\right)\left\{S_{t}\left(\gamma_{2}, y_{t-1}\right) \rho_{1}+\left(1-S_{t}\left(\gamma_{2}, y_{t-1}\right)\right) \rho_{2}\right\} y_{t-1}+\sum_{i=1}^{k} k_{i} \Delta y_{t-i}+\varepsilon_{i}
$$

Here, $G\left(\gamma_{1}, y_{t-1}\right)=1-\exp \left(-\gamma_{1}\left(y_{t-1}^{2}\right)\right)$ with $\gamma_{1} \geq 0$ and $S_{t}\left(\gamma_{2}, y_{t-1}\right)=\left\{1+\exp \left(-\gamma_{2} y_{t-1}\right)\right\}^{-1}$ with $\gamma_{2} \geq 0$.

The model for Taylor approximations as it was for KSS tests is as follows [16]:

$$
\Delta y_{t}=a\left(\rho_{2}^{*}-\rho_{1}^{*}\right) \gamma_{1} \gamma_{2} y_{t-1}^{4}+\rho_{2}^{*} \gamma_{1} y_{t-1}^{3}+\eta_{i}
$$

where $\rho_{1}^{*}$ ve $\rho_{2}^{*}$ are linear function of $\rho_{1}$ and $\rho_{2}$. Where $a=1 / 4$, which can be written

$$
\Delta y_{t}=\phi_{1} y_{t-1}^{3}+\phi_{2} y_{t-1}^{4}+\eta_{i}
$$

where $\phi_{1}=\rho_{2}^{*} \gamma_{1}$ and $\phi_{2}=a\left(\rho_{2}^{*}-\rho_{1}^{*}\right) \gamma_{1} \gamma_{2}$. An augmented version is

$$
\Delta y_{t}=\phi_{1} y_{t-1}^{3}+\phi_{2} y_{t-1}^{4}+\sum_{i=1}^{k} k_{i} \Delta y_{t-i}+\eta_{i}
$$


where $y_{t}$, similar KSS test, is raw, demeaned or detrended data. The null hypothesis of nonstationarity is $H_{0}: \phi_{1}=\phi_{2}=0$. Sollis [16] derives the asymptotic distribution of an F test of $H_{0}: \phi_{1}=\phi_{2}=0$ which shows it to be nonsdandard function of Brownian motions. The test statistic can be written as follows:

$$
F=(R \hat{\beta}-r)^{\prime}\left[\hat{\sigma}^{2} R\left\{\sum_{t} x_{t} x_{t}^{\prime}\right\}^{-1} R^{\prime}\right]^{-1}(R \hat{\beta}-r) / m
$$

The critical values of $\mathrm{F}$ statistic are tabulated by Sollis [16]. When the null hypothesis is rejected, the null hypothesis of symmetric ESTAR, $H_{0}: \phi_{2}=0$, can be tested against the alternative of asymmetric ESTAR, $H_{0}: \phi_{2} \neq 0$, by means of standard hypotheses test. For standard F critical values to be applicable for this test, $\phi_{1}<0$, so that under the null being tested the series is stationary [16].

\subsubsection{Linear Unit Root Test with Structural Breaks}

Narayan and Popp [17] propose two different model specifications. The first model allows for two breaks in level (M1), and the other allows for two breaks in level as well as the slope (M2). The main difference between two model specification is to determine $d_{t}$ deterministic component. Narayan and Popp [17] define $d_{t}$ deterministic component as follows for model M1 and M2, respectively.

$$
\begin{aligned}
& d_{t}^{M_{1}}=\alpha+\beta t+\Psi^{*}(L)\left(\theta_{1} D U_{1, t}^{\prime}+\theta_{2} D U_{2, t}^{\prime}\right) \\
& d_{t}^{M_{2}}=\alpha+\beta t+\Psi^{*}(L)\left(\theta_{1} D U_{1, t}^{\prime}+\theta_{2} D U_{2, t}^{\prime}+\gamma_{1} D T_{1, t}^{\prime}+\gamma_{2} D T_{2, t}^{\prime}\right)
\end{aligned}
$$

where $D U_{1, t}^{\prime}=1\left(t>T_{B, i}^{\prime}\right), \quad D T_{1, t}^{\prime}=1\left(t>T_{B, i}^{\prime}\right)\left(t-T_{B, i}^{\prime}\right), i=1,2 . \quad T_{B, i}^{\prime}, i=1,2$, denotes the true break dates. The parameters, $\theta_{i}$ and $\gamma_{i}$ indicate the magnitude of the level and slope breaks, respectively.

The test equation used for Model 1 (M1) that allows for two structural breaks in level in mean is presented below.

$$
\begin{aligned}
y_{t}^{M_{1}}= & \rho y_{t-1}+\alpha_{1}+\beta^{*} t+\theta_{1} D\left(T_{B}^{\prime}\right)_{1, t}+\theta_{2} D\left(T_{B}^{\prime}\right)_{2, t} \\
& +\delta_{1} D U_{1, t-1}^{\prime}+\delta_{2} D U_{2, t-1}^{\prime}+\sum_{j=1}^{k} \beta_{j} \Delta y_{t-j}+e_{t}
\end{aligned}
$$

where $\alpha_{1}=\Psi^{*}(1)^{-1}[(1-\rho) \alpha+\rho \beta]+\Psi^{* \prime}(1)^{-1}(1-\rho) \beta, \quad \Psi^{*}(1)^{-1}$ being the mean lag, $\beta^{*}=\Psi^{*}(1)^{-1}(1-\not p) \beta, \phi=\rho-1, \delta_{i}=-\phi \theta_{i}$ and $D\left(T_{B}^{\prime}\right)_{i, t}=1\left(t=T_{B, i}^{\prime}+1\right), i=1,2, \cdots$.

$T_{B, i}^{\prime}, i=1,2$, denotes true break dates. The break dates are selected using sequential procedure that selects the break dates when the absolute $t$-value of the break dummy coefficients is maximized.

The test equation used for Model 2 (M2) that allows for two structural breaks $\mathrm{n}$ level on average and in trend is presented below.

$$
\begin{aligned}
y_{t}^{M_{2}}= & \rho y_{t-1}+\alpha^{*}+\beta^{*} t+\kappa_{1} D\left(T_{B}^{\prime}\right)_{1, t}+\kappa_{2} D\left(T_{B}^{\prime}\right)_{2, t}+\delta_{1}^{*} D U_{1, t-1}^{\prime} \\
& +\delta_{2}^{*} D U_{2, t-1}^{\prime}+\gamma_{1}^{*} D T_{1, t-1}^{\prime}+\gamma_{2}^{*} D T_{2, t-1}^{\prime}+\sum_{j=1}^{k} \beta_{j} \Delta y_{t-j}+e_{t}
\end{aligned}
$$

where $\kappa_{i}=\left(\theta_{i}+\gamma_{i}\right), \quad \delta_{i}^{*}=\left(\gamma_{i}-\phi \theta_{i}\right)$ and $\gamma_{i}^{*}=-\phi \gamma_{i}, \quad i=1,2$.

The $t$ statistics of the $\hat{\rho}$ parameter is used to test the null hypothesis of unit 
root against the $\rho=1, \rho<1$ alternative hypothesis. The test critical values are tabulated in Narayan and Popp [17].

\section{Empirical Findings}

We reviewed whether the series to examine at the first stage of the study for convergence were linear or not by using the test developed by Harvey et al., [13]. Table 1 presents the results.

According to the results in Table 1, while Australia, France, Germany, Italy, Japan, North Korea, Luxembourg, Spain, Sweden, Turkey, UK, and the USA are

Table 1. Linearity tests results.

\begin{tabular}{|c|c|}
\hline Country & Harvey Statistics \\
\hline Australia & $5.31^{*}$ \\
\hline Austria & 1.25 \\
\hline Belgium & 2.79 \\
\hline Canada & 3.20 \\
\hline Chile & 2.48 \\
\hline Denmark & 0.08 \\
\hline Finland & 0.66 \\
\hline France & $4.76^{\star}$ \\
\hline Germany & $7.59^{*}$ \\
\hline Greece & 1.64 \\
\hline Ireland & 1.25 \\
\hline Italy & $314.17^{\star}$ \\
\hline Japan & $5.55^{\star}$ \\
\hline North Korea & $6.95^{\star}$ \\
\hline South Korea & 3.95 \\
\hline Luxembourg & $6.25^{\star}$ \\
\hline Mexico & 1.64 \\
\hline Netherlands & 3.48 \\
\hline New Zealand & 1.31 \\
\hline Norway & 1.68 \\
\hline Portugal & 2.96 \\
\hline Spain & $5.64^{*}$ \\
\hline Sweden & $6.69^{*}$ \\
\hline Switzerland & 0.49 \\
\hline Turkey & $13.03^{*}$ \\
\hline UK & $12.94^{*}$ \\
\hline USA & $5.47^{\star}$ \\
\hline
\end{tabular}

Note: The symbols ${ }^{*},{ }^{* *}$, and ${ }^{* * *}$ mean rejection of the null hypothesis of linearity at the $1 \%, 5 \%$, and $10 \%$ respectively. Harvey et al. (2008) test critical values, $9.21,5.99$ and 4.60 respectively. 
Table 2. Nonlinear unit root tests results.

\begin{tabular}{ccccccccc}
\hline & \multicolumn{1}{c}{ KSS } & \multicolumn{2}{c}{ Kruse } & \multicolumn{2}{c}{ Sollis } \\
\hline & $\mathrm{k}$ & Stat & $\mathrm{k}$ & Stat & $\mathrm{k}$ & Ho: $\phi_{1}=\phi_{2}=0$ & Ho: $\phi_{2}=0$ & $\mathrm{p}$ value \\
\hline Australia & 1 & -1.96816 & 1 & $9.388311^{\mathrm{c}}$ & 1 & $7.795929^{\mathrm{a}}$ & 3.567142 & 0.0697 \\
France & 2 & -1.88583 & 2 & 3.647676 & 2 & 3.534421 & 0.101031 & 0.7532 \\
Germany & 1 & -2.59058 & 1 & 8.088011 & 1 & $8.148822^{\mathrm{a}}$ & 1.353101 & 0.2549 \\
Italy & 1 & 0.271862 & 1 & 3.016651 & 1 & 2.529186 & 2.451304 & 0.1295 \\
Japan & 3 & -1.4322 & 3 & 2.305626 & 3 & 2.140589 & 0.161094 & 0.6919 \\
North Korea & 1 & -2.19993 & 1 & 4.688372 & 1 & $5.149429^{\mathrm{b}}$ & 0.411479 & 0.5266 \\
Luxembourg & 1 & -1.73606 & 1 & 2.924167 & 1 & 3.031412 & 0.112972 & 0.7394 \\
Spain & 2 & -0.67941 & 2 & 1.688755 & 2 & 0.611304 & 0.164543 & 0.6885 \\
Sweden & 2 & 0.478338 & 3 & 1.74167 & 3 & 1.402575 & 1.393938 & 0.2498 \\
Turkey & 2 & -0.79225 & 1 & $15.49859^{\mathrm{a}}$ & 1 & $12.79519^{\mathrm{a}}$ & 3.065895 & 0.0913 \\
UK & 1 & 0.004095 & 1 & 7.713567 & 1 & 3.707096 & 3.707077 & 0.0648 \\
USA & 2 & $-2.92075^{\mathrm{c}}$ & 2 & 8.302401 & 2 & $8.302401^{\mathrm{a}}$ & 0.075079 & 0.7863 \\
\hline
\end{tabular}

Note: The symbols ${ }^{\mathrm{a}},{ }^{\mathrm{b}}$ and ${ }^{\mathrm{c}}$ mean rejection of the null hypothesis of unit root at the $1 \%, 5 \%$ and $10 \%$ respectively. KSS: $-3.48,-2.93,-2.66$; KRUSE: $13.75,10.17,8.6$; Sollis: $6.883,4.954,4.157$.

nonlinear, Austria, Belgium, Canada, Chile, Denmark, Finland, Greece, Ireland, South Korea, Mexico, Netherlands, New Zealand, Norway, Portugal, Switzerland are not nonlinear. By using this basic finding, convergence is investigated for the countries having nonlinear data using the tests of Kapetanios et al., [14], Kruse [15] and Sollis [16]. Table 2 shows the results.

The first part of Table 2 belongs to the test of Kapetanios et al., [14]. According to these test findings, only energy intensity of USA converges to OECD average. The second part of Table 2 includes the findings concerning to Kruse test [15]. According to these results, energy intensity of Australia and Turkey converge to OECD average. The final part of Table 2 belongs to the test results developed by Sollis [16]. According to these results, energy intensity data of Australia, Germany, North Korea, Turkey, and the USA converges to OECD average. Also, there is the asymmetric effect on Australia and Turkey. We used Narayan and Popp [17] test for the series on which linearity finding was obtained. Table 3 shows the results.

According to the results in Table 3, energy intensity in Austria, Belgium, Canada, Denmark, and Norway converges to OECD average. The convergence is not beside the mark for Chile, France, Finland, Greece, Ireland, Italy, Japan, South Korea, Mexico, Netherlands, New Zealand, Portugal, and Switzerland.

\section{Conclusions}

The oil crises experienced in the 1970s revealed the importance of the energy in the world economy and how energy impacts global markets in so many different ways. The energy intensity is the measurement used for the energy efficiency. Energy intensity is measured by the ratio of total energy consumption to total 
Table 3. Linear unit root tests results.

\begin{tabular}{ccccc}
\hline Country & $\mathbf{k}$ & t-statistic & TB1 & TB2 \\
\hline Austria & 5 & $-4.907^{\mathrm{b}}$ & 1994 & 2000 \\
Belgium & 3 & $-4.797^{\mathrm{b}}$ & 1991 & 1996 \\
Canada & 0 & $-4.392^{\mathrm{b}}$ & 1991 & 1999 \\
Chile & 0 & -1.968 & 1990 & 1996 \\
Denmark & 0 & $-4.232^{\mathrm{c}}$ & 1995 & 1999 \\
Finland & 2 & -3.262 & 1990 & 1994 \\
Greece & 5 & -2.833 & 1997 & 2003 \\
Ireland & 2 & -2.296 & 1987 & 2002 \\
South Korea & 0 & -1.859 & 1988 & 1996 \\
Mexico & 0 & -2.662 & 1989 & 1996 \\
Netherlands & 4 & -2.796 & 1997 & 2003 \\
New Zealand & 2 & -3.819 & 1995 & 2002 \\
Norway & 3 & $-4.527^{\mathrm{b}}$ & 1993 & 1995 \\
Portugal & 0 & -2.351 & 1990 & 1993 \\
Switzerland & 0 & -1.500 & 1998 & 2000 \\
\hline
\end{tabular}

Note: The symbols ${ }^{*}, *$, and ${ }^{* * *}$ mean rejection of the null hypothesis of a unit root at the $1 \%, 5 \%$, and $10 \%$ respectively. Critical values are $-5.259,-4.514,-4.143$ at the $1 \%, 5 \%$, and $10 \%$, respectively. TB1 and TB2 denote the structural break dates suggested by the tests.

output (GDP). In this study, we reviewed the convergence of energy intensity in OECD countries.

We used nonlinearity test developed by Harvey et al., [13] to determine whether series were nonlinear or not. We reviewed convergence status by using the tests of Kapetanios et al., [14], Kruse [15] and Sollis [16] among the nonlinear unit root tests for the series where nonlinearity was determined. We did the analysis using the two structural breaks tests developed by Narayan and Popp [17] for linear series. According to our findings, convergence is not beside the mark for Chile, Finland, Greece, Ireland, South Korea, Luxembourg, Mexico, Netherlands, New Zealand, Portugal, Spain, Sweden, Switzerland, and the UK. The relevant countries should make changes to their energy policies to achieve effective energy use.

\section{References}

[1] Cheng, B.S. (1995) An Investigation of Cointegration and Causality between Energy Consumption and Economic Growth. Journal of Energy and Development, 21.

[2] Lee, C.-C. and Chang, C.-P. (2008) Energy Consumption and Economic Growth in Asian Economies: A More Comprehensive Analysis Using Panel Data. Resource and Energy Economics, 30, 50-65. https://doi.org/10.1016/j.reseneeco.2007.03.003

[3] Mehrara, M. (2007) Energy Consumption and Economic Growth: The Case of Oil Exporting Countries. Energy Policy, 35, 2939-2945. https://doi.org/10.1016/j.enpol.2006.10.018 
[4] Paul, S. and Bhattacharya, R.N. (2004) Causality between Energy Consumption and Economic Growth in India: A Note on Conflicting Results. Energy Economics, 26, 977-983. https://doi.org/10.1016/j.eneco.2004.07.002

[5] Nilsson, L.J. (1993) Energy Intensity Trends in 31 Industrial and Developing Countries 1950-1988. Energy, 18, 309-322. https://doi.org/10.1016/0360-5442(93)90066-M

[6] Pen, Y.L. and Sevi, B. (2010) On the Non-Convergence of Energy Intensities: Evidence from a Pair-Wise Econometric Approach. Ecological Economics, 69, 641-650. https://doi.org/10.1016/j.ecolecon.2009.10.001

[7] Liddle, B. (2010) Revisiting World Energy Intensity Convergence for Regional Differences. Applied Energy, 87, 3218-3225. https://doi.org/10.1016/j.apenergy.2010.03.030

[8] Ezcurra, R. (2007) Distribution Dynamics of Energy Intensities: A Cross-Country Analysis. Energy Policy, 35, 5254-5259. https://doi.org/10.1016/j.enpol.2007.05.006

[9] Ghirmay, T. (2014) Economic Integration and Convergence: The Case of Central Appalachia in the US. The Southwestern Economic Review, 41, 63-78.

[10] Barro, R.J. and Sala-i-Martin, X. (1992) Convergence. Journal of Political Economy, 100, 223-251. https://doi.org/10.1086/261816

[11] Carlino, G. and Mills, L. (1993) Are U.S. Regional Incomes Converging? A Time Series Analysis. Journal of Monetary Economics, 32, 335-346.

https://doi.org/10.1016/0304-3932(93)90009-5

[12] Bernard, A.B. and Durlauf, S.N. (1995) Convergence in International Output. Journal of Applied Econometrics, 10, 97-108. https://doi.org/10.1002/jae.3950100202

[13] Harvey, D.I., Leybourne, S.J. and Xiao, B. (2008) A Powerful Test for Linearity When the Order of Integration Is Unknown. Studies in Nonlinear Dynamics \& Econometrics, 12, 1582. https://doi.org/10.2202/1558-3708.1582

[14] Kapetanios, G., Shin, Y. and Snell, A. (2003) Testing for a Unit Root in the Nonlinear STAR Framework. Journal of Econometrics, 112, 359-379. https://doi.org/10.1016/S0304-4076(02)00202-6

[15] Kruse, R. (2011) A New Unit Root Test against ESTAR-Based on a Class of Modified Statistics. Statistical Papers, 52, 71-85. https://doi.org/10.1007/s00362-009-0204-1

[16] Sollis, R. (2009) A Simple Unit Root Test against Asymmetrical STAR Nonlinearity with an Application to Real Exchange Rates in Nordic Countries. Economic Modelling, 26, 118-125. https://doi.org/10.1016/j.econmod.2008.06.002

[17] Narayan, P.K. and Popp, S. (2010) A New Unit Root Test with Two Structural Breaks in Level and Slope at Unknown Time. Journal of Applied Statistics, 37, 1425 1438. https://doi.org/10.1080/02664760903039883

[18] Enders, W. and Granger, C.W.J. (1998) Unit-Root Tests and Asymmetric Adjustment with an Example Using the Term Structure of Interest Rates. Journal of Business and Economic Statistics, 16, 304-311.

[19] Perron, P. (1989) The Great Crash, the Oil Price Shock, and the Unit-Root Hypothesis. Econometrica, 57, 1361-1401. https://doi.org/10.2307/1913712

[20] Cuestas, J.C. and Garratt, D. (2011) Is Real GDP Per Capita a Stationary Process? Smooth Transitions, Nonlinear Trends, and Unit Root Testing. Empirical Economics, 41, 555-563. https://doi.org/10.1007/s00181-010-0389-0

[21] Narayan, P.K. and Popp, S. (2013) Size and Power Properties of Structural Break Unit Root Tests. Applied Economics, 45, 721-728. 
https://doi.org/10.1080/00036846.2011.610752

[22] Abadir, K.M. and Distanso, W. (2007) Testing Joint Hypotheses When One of the Alternatives Is One Sided. Journal of Econometrics, 140, 695-718.

https://doi.org/10.1016/j.jeconom.2006.07.022

[23] Cuestas, J.C. and Ramlogan-Dobson, C. (2013) Convergence of Inflationary Shocks: Evidence from the Caribbean. The World Economy, 36, 1229-1243.

https://doi.org/10.1111/twec.12082

Submit or recommend next manuscript to SCIRP and we will provide best service for you:

Accepting pre-submission inquiries through Email, Facebook, LinkedIn, Twitter, etc. A wide selection of journals (inclusive of 9 subjects, more than 200 journals)

Providing 24-hour high-quality service

User-friendly online submission system

Fair and swift peer-review system

Efficient typesetting and proofreading procedure

Display of the result of downloads and visits, as well as the number of cited articles Maximum dissemination of your research work

Submit your manuscript at: http://papersubmission.scirp.org/

Or contact me@scirp.org 